\title{
Interferensi Gramatikal Bahasa Indonesia dalam Mahārah Kalām Santriwati KMI Pondok Modern Ar-Risalah Ponorogo
}

\author{
Jauharotun Ni'mah \\ Sekolah Tinggi Agama Islam At-Tanwir Bojonegoro \\ imaa2jauhanie@gmail.com
}

DOI: http://dx.doi.org/10.18326/lisania.v2i2.121-138

\begin{abstract}
Language plays an important role in human life. language and humans can not be separated. Humans in all their activities need language to communicate with other humans. Communication has various kinds, one of which is oral communication that can cause interference. This research is descriptive in qualitative form. In this study the author uses listening method, the basic technique is "Tapping Technique". The advanced technique I is checking out the free involvement technique or "SBLC". Advanced technique II is a note-taking technique. Another technique is interview. The emphasis of the analysis in this study is the grammatical interference of Bahasa Indonesia in mahārah kalām, of female students (santriwati) of Kulliyatul Mu'allimat Al-Islamiyah (KMI) at Ar-Risalah International Program of modern boarding school Ponorogo. Based on the emphasis of the analysis above, the authors chose the intralingual equivalent method as an analysis method. The presentation method of the data results analysis used in this study is an informal method. The results show that the form of Interference that occurs in the study location is in the form of morphological and syntactic interference. As for the factor underlying the interference in mahārah kalām of Santriwati at KMI Ar-Risalah boarding school is the difference in the system of first language or second language (interlingual transfer), analogy (excessive equation), thinness of user loyalty to recipient languages, the need for synonyms and transfer language because it brings habits in mother tongue.
\end{abstract}

Keywords: Grammatical Interference, Indonesian, Mahārah Kalām

\begin{abstract}
Abstrak
Bahasa berperan penting bagi kehidupan manusia. Antara bahasa dan manusia tidak bisa dipisahkan. Manusia dalam segala aktivitasnya memerlukan bahasa untuk berkomunikasi dengan manusia yang lain. Komunikasi mempunyai berbagai macam ragam, salah satunya yaitu komunikasi lisan yang dapat menyebabkan interferensi. Penelitian ini adalah bersifat deskriptif dengan bentuk kualitatif. Dalam penelitian ini penulis menggunakan metode simak, teknik dasarnya adalah "Teknik Sadap". Teknik lanjutan I adalah teknik simak bebas libat cakap atau "SBLC". Teknik lanjutan II adalah teknik catat. Teknik lainnya adalah dengan wawancara. Penekanan analisis pada penelitian ini adalah interferensi gramatikal bahasa Indonesia dalam mahārah kalām Santriwati KMI Pondok Modern Ar-Risalah Program Internasional Ponorogo. Berdasarkan penekanan analisis di atas maka penulis memilih metode padan intralingual sebagai metode analisis. Metode pemaparan hasil analisis data yang digunakan dalam penelitian ini adalah metode yang bersifat informal. Hasil penelitian menunjukkan bahwa bentuk-betuk Interferensi yang terjadi di lokasi penelitian berupa interferensi morfologi dan sintaksis. Adapun faktor-faktor yang melatarbelakangi terjadinya interferensi dalam mahārah kalām Santriwati KMI Pondok Modern Ar-
\end{abstract}


Risalah adalah perbedaan sistem bahasa pertama atau bahasa kedua (interlingual transfer), analogi (persamaan yang berlebihan), tipisnya kesetiaan pemakai bahasa penerima, kebutuhan akan sinonim dan transfer struktur bahasa karena terbawanya kebiasaan dalam bahasa ibu.

Kata kunci: Interferensi gramatikal, Bahasa Indonesia, Mahārah Kalām

\section{Pendahuluan}

Bahasa pada saat ini telah menjadi suatu budaya yang patut dilestarikan keberadaannya. Fungsi umum bahasa adalah sebagai alat komunikasi sosial. Di dalam masyarakat ada komunikasi atau saling hubungan antar anggota. Untuk keperluan itu dipergunakan suatu wahana yang dinamakan bahasa. Dengan demikian setiap masyarakat dipastikan memiliki dan menggunakan alat komunikasi sosial tersebut. Tidak ada masyarakat tanpa bahasa dan tidak ada pula bahasa tanpa masyarakat (Soeparno, 2002: 5). Belajar bahasa merupakan suatu kewajiban bagi semua orang. Dengan belajar bahasa berarti juga belajar membudidayakan diri sendiri, mengembangkan diri, dan membentuk diri menjadi manusia yang luhur (Sanjaya, 2014).

Lebih dari setengah penduduk dunia adalah dwibahasawan. Hal ini berarti bahwa sebagian besar manusia dibumi ini menggunakan dua bahasa sebagai alat komunikasi. Orang yang biasa menggunakan dua bahasa atau lebih secara bergantian untuk tujuan yang berbeda pada hakikatnya merupakan agen pengontak dua bahasa. Semakin besar jumlah orang yang seperti ini maka semakin intensif pula kontak antara dua bahasa yang mereka gunakan. Kontak ini menimbulkan saling pengaruh, yang manifestasinya menjelma di dalam penerapan kaidah bahasa pertama (B1) di dalam penggunaan bahasa asing (foreign language). Keadaan sebaliknya pun dapat terjadi di dalam pemakaian sistem bahasa asing (foreign language) pada saat menggunakan B1. Salah satu dampak negatif dari praktek penggunaan dua bahasa secara bergantian adalah terjadinya kekacauan pemakaian bahasa, yang lebih dikenal dengan istilah interferensi (Guntur Tarigan \& Djogo, 2011: 2-3). Eksistensi interferensi menimbulkan kekaburan dalam pemakaian bahasa, untuk itulah sebagai suatu konsekuensi logis bahwa interferensi itu sedapat mungkin harus dihindari bahkan ditiadakan. Dengan demikian, akan lebih mudah dimengerti ketika seorang penutur menggunakan bahasa asing secara baik dan benar sesuai dengan kaidah dan sistem yang berlaku dalam pemakaian bahasa asing. 
Bahasa Arab merupakan bahasa asing yang telah lama dipelajari oleh para pembelajar bahasa di Indonesia. Bahasa Arab juga telah diajarkan pada setiap tingkat pendidikan tidak terkecuali di pondok pesantren Ar-Risalah yang menerapkan bahasa asing tersebut dalam proses pembelajarannya, baik di kelas maupun di luar kelas. Seorang penutur bahasa Arab yang berbahasa ibu Indonesia sering memindahkan unsur bahasa Indonesia ke dalam bahasa Asing yang dipelajarinya. Unsur ini terpaksa dipergunakan karena dia belum memahami unsur yang seharusnya dipergunakan di dalam bahasa asing itu. Unsur-unsur ini dapat berupa ciri-ciri khusus dan kaidah yaitu morfologi dan sintaksis. Apabila pemindahan penggunaan unsur-unsur tertentu secara tetap itu menghambat pengembangan belajar bahasa asing itu, pemindahan itu disebut interferensi.

Salah satu permasalahan yang esensial dihadapi dalam penguasaan bahasa Arab selama ini adalah faktor lingual, yakni munculnya interferensi bahasa pertama pembelajar. Di dalam penelitian ini kasus penguasaan bahasa Arab di angkat dari kenyataan para santriwati Kulliyatul Mu'allimat Al-Islamiyah (KMI) di Pondok Modern Ar-Risalah Program Internasional Ponorogo dengan bahasa ibu pembelajar bahasa Indonesia. Berkenaan dengan itu yang disoroti dalam pembahasan penelitian ini adalah interferensi gramatikal bahasa Indonesia terhadap Mahārah Kalām. Namun demikian, tidak menutup kemungkinan akan terjadinya interferensi dengan bahasa lain, baik bahasa daerah pembelajar dan bahasa asing lainnya yaitu bahasa Inggris. Dalam hal ini penulis lebih memfokuskan penelitian pada penggunaan bahasa Indonesia dalam Mahārah Kalām.

Dari data yang penulis peroleh, masih banyaknya pengaruh pemakaian bahasa Indonesia yang frekuensi waktunya lebih lama daripada bahasa Arab. Pengaruh itu tampak ketika berkomunikasi misalnya struktur bahasa Indonesia yang masuk dalam komunikasi mereka. Dalam mahārah kalām sering ditemukan penggunaan bahasa Arab yang strukturnya masih menggunakan struktur bahasa Indonesia. Seperti dalam mengungkapkan kalimat "kamu sedikit-sedikit marah" kebanyakan para pelajar bahasa Arab akan mengungkapkannya dengan kalimat أنت قليل قليل تغضب, seharusnya pelajar dapat mengungkapkannya dengan ungkapan بعد كل مرة وأنت تغضبين .

Hal tersebut secara langsung menimbulkan dampak yang kurang baik atau negatif akibat penerapan struktur bahasa Indonesia ke dalam komunikasi berbahasa Arab. Di samping itu kurang adanya kejelian dari pihak guru ataupun pendamping santri yang 
membenarkan kesalahan santriwati dalam berbahasa sehingga kesalahan tersebut terus berlarut-larut sehingga belum ditemukan solusi yang tepat untuk membenarkannya. Oleh karena itu, dari data di atas menurut penulis perlu dilakukan penelitian untuk menganalisis interferensi gramatikal Bahasa Indonesia dalam mahārah kalām santriwati KMI Ponpes Ar-Risalah dan solusinya. Sehingga pendidik dapat mengetahui dan mengajarkan bahasa Arab yang baik agar tidak terjadi interferensi dalam pembelajaran bahasa Arab.

Telah banyak pengkajian dan penelitian dalam bidang kalām .Tetapi penelitian kalām yang berkaitan dengan Sosiolinguistik masih jarang ditemukan dalam lingkup Bahasa Arab. Oleh karena itu perlu dilakukan penelitian interferensi gramatikal Bahasa Indonesia dalam mahārah kalām. Dengan dilakukannya penelitian ini diharapkan dapat memperkaya pengetahuan bagi insan yang bergelut di bidang bahasa Arab. Selain itu penulis berharap penelitian ini dapat dijadikan rujukan bagi para pelajar dan pendidik Bahasa Arab untuk lebih teliti dalam belajar maupun mengajarkan bahasa Arab. Sehingga dapat mengurangi interferensi bahasa dalam keterampilan bahasa yang dimiliki seseorang.

Berdasarkan asumsi di atas maka, penelitian ini bertujuan untuk mengetahui bagaimana bentuk interferensi gramatikal Bahasa Indonesia dalam mahārah kalām Santriwati KMI Pondok Modern Ar-Risalah Program Internasional Ponorogo dan apa saja faktor-faktor apa saja yang melatarbelakangi interferensi gramatikal bahasa Indonesia dalam mahārah kalām Santriwati KMI Pondok Modern Ar-Risalah Program Internasional Ponorogo.

Penelitian ini dapat memberikan manfaat baik teoritis maupun praktis. Dari segi manfaat praktis, penelitian ini diharapkan dapat memberikan masukan dan sumbangan pengetahuan pada para santriwati yang sedang mengalami proses pembelajaran bahasa asing. Hasil penelitian ini juga diharapkan bermanfaat untuk orang-orang yang berkecimpung dalam dunia pendidikan. Mereka diharapkan dapat lebih memahami secara mendalam pengetahuan tentang kebahasaan terutama interferensi dan pada akhirnya dapat menerapkan bahasa tersebut dengan baik dan benar, sesuai dengan situasi, tempat dan dengan siapa penutur berkomunikasi.

Secara teoritis penelitian ini diharapkan dapat menambah khasanah ilmu pengetahuan Linguistik terutama kajian Sosiolinguistik perihal interferensi. Interferensi yang dikaji adalah interferensi gramatikal bahasa Indonesia dalam mahārah kalām. 


\section{Metode Penelitian}

Penelitian ini menggunakan pendekatan kualitatif. Dikatakan kualitatif karena penelitian ini sesuai dengan beberapa ciri rancangan kualitatif yakni: latar alamiah, manusia sebagai alat (instrumen), metode kualitatif, analisis data secara induktif, teori dari dasar, dan deskriptif (Moleong, 2012: 8-11). Jadi, dengan pendekatan kualitatif ini penulis akan menemukan data-data yang dikumpulkan kemudian di analisis, yang akan memunculkan teori-teori yang relevan untuk acuan penulis.

Jenis penelitian yang digunakan didalam penelitian ini adalah penelitian lapangan (field research) yang dilakukan di lokasi, tempat objek penelitian itu berada. Oleh sebab itu, penelitian ini merupakan penelitian deskriptif karena penelitian ini berdasarkan fakta yang ada dan secara empiris, hidup pada penutur-penuturnya (Sudaryanto, 1988: 62). Berdasarkan definisi tersebut, dalam penelitian ini akan dideskripsikan interferensi gramatikal Bahasa Indonesia dalam mahārah kalām Santriwati Kulliyatul Mu'allimat AlIslamiyah Pondok Modern Ar-Risalah Program Internasional Ponorogo. Untuk mendapatkan data, penelitian ini menggunakan berbagai metode dan teknik yang sesuai dengan karakteristik penelitian.

Penelitian tentang interferensi gramatikal bahasa Indonesia dalam mahārah kalām Santriwati KMI Pondok Modern Ar-Risalah Program Internasional akan mengambil lokasi penelitian di Pondok Modern Arrisalah yang terletak di kabupaten Ponorogo dan berlokasi di desa Gundik kecamatan Slahung kabupaten Ponorogo. Lokasi ini dipilih karena mempunyai keistimewaan, terutama yang berkaitan dengan bahasa. Pondok Modern Ar-risalah adalah lembaga Pendidikan Islam yang menyelenggarakan pendidikan dan pengajaran dengan sistem asrama atau yang lebih dikenal dengan Pondok Pesantren (Islamic Boarding School).

Dalam penelitian ini, populasi yang mungkin dijadikan subyek penelitian adalah seluruh santriwati pondok. Dari data yang terkumpul sampai bulan Oktober 2014, jumlah Santriwati Kulliyatul Mu'allimat Al-Islamiyah Pondok Modern Ar-Risalah Program Internasional Ponorogo adalah 287 orang. Dari populasi tersebut kemudian di ambil sampel yang sekiranya dapat mewakili seluruh populasi. Dengan demikian, realitas dan fenomena kebahasaan yang muncul di kalangan santriwati dapat direkam dengan lebih akurat. Sedangkan teknik pengambilan sampel menggunakan purposive sampling. Dimana menurut Moleong pengambilan sampel secara purposive lebih layak 
digunakan dalam penelitian kualitatif daripada penentuan secara acak (Moleong, 2012: 165).

Adapun sumber data yang digunakan dalam penelitian ini terbagi menjadi dua yaitu sumber data primer dan sumber data sekunder. Sumber data primer yang digunakan oleh penulis adalah Santriwati Kulliyatul Mu'allimat Al-Islamiyah di Pondok Modern Ar-Risalah Program Internasional Ponorogo yang merupakan dwi bahasawan. Sumber data ini untuk mengetahui bahasa lisan yang mengalami interferensi. Sumber data sekunder yang digunakan oleh peneliti adalah buku, jurnal ilmiah, kamus, dan buku-buku yang relevan dengan penelitian yaitu tentang interferensi bahasa.

Adapun metode pengumpulan data dalam penelitian ini meliputi observasi, dalam istilah lain, metode ini juga disebut dengan metode simak (Mahsun, 2012: 242). Dikatakan simak karena dilakukan dengan menyimak penggunaan bahasa dalam mahārah kalām. Metode ini memiliki teknik dasar yang berwujud teknik sadap. Teknik sadap disebut teknik dasar karena pada hakikatnya penyimakan diwujudkan dengan penyadapan. Dalam arti, penulis dalam upaya mendapatkan data dilakukan dengan penyadapan bahasa seseorang atau beberapa orang. Sebagai teknik dasar maka ia memiliki teknik lanjutan berupa simak bebas libat cakap. Teknik simak bebas libat cakap maksudnya penulis hanya berperan sebagai pengamat dan tidak terlibat dalam proses pertuturan (Mahsun, 2012: 242). Teknik ini digunakan untuk menyimak tuturan lisan para santriwati. Yang disimak adalah data interferensi gramatikal Bahasa Indonesia dan bahasa Arab Santriwati KMI di Pondok Modern Ar-Risalah Program Internasional Ponorogo.

Setelah dilakukan penyimakan dan ditentukan objek yang diamati, dilakukan perekaman terhadap percakapan dalam Mahārah Kalām yang dilakukan oleh Santriwati Kulliyatul Mu'allimat Al-Islamiyah di Pondok Modern Ar-Risalah Program Internasional Ponorogo dengan voice recorder. Selain itu, agar data bahasa santri bersifat alami penulis juga menggunakan spy cam recorder dan spy paper. Hal ini dilakukan untuk memperoleh data sesuai rumusan masalah pertama dan kedua. Yang direkam adalah data interferensi gramatikal bahasa Indonesia dan bahasa Arab.

Setelah perekaman berhasil dilakukan, teknik selanjutnya adalah teknik catat. Teknik catat dilakukan untuk mencatat penggalan tuturan percakapan dalam percakapan santriwati. Selanjutnya tuturan lisan ditranskripkan dalam bentuk catatan. Fokus bahasa yang diteliti adalah interferensi gramatikal bahasa Indonesia dan bahasa 
Arab. Interferensi merupakan salah satu aspek ketergantungan bahasa (language dependency) dalam masyarakat multilingual. Dalam masyarakat multilingual sangat sulit seorang penutur mutlak hanya menggunakan satu bahasa. Untuk mendapatkan hasil yang lebih baik, metode observasi atau simak ini akan didukung dengan teknikteknik penelitian. Di antara teknik-teknik tersebut adalah teknik wawancara. Patton membagi teknik wawancara menjadi tiga cara, yaitu: wawancara pembicaraan informal, wawancara menggunakan petunjuk umum, dan wawancara baku terbuka (Moleong, 2012: 187). Dalam teknik wawancara ini yang dicatat adalah data sesuai dengan faktorfaktor penyebab interferensi gramatikal bahasa Indonesia dan bahasa Arab.

Data yang sudah terkumpul, kemudian dianalisis dengan menggunakan metode padan intralingual. Metode padan intralingual adalah metode analisis dengan cara menghubung-bandingkan unsur-unsur yang bersifat lingual, baik yang terdapat dalam satu bahasa maupun dalam beberapa bahasa yang berbeda (Mahsun, 2012: 118). Penyajian hasil analisis data dalam penelitian ini dilakukan dengan menggunakan metode informal. Penyajian informal yaitu berupa rumusan dengan menggunakan katakata biasa (Sudaryanto, 1993: 145). Alasan digunakannya metode informal dalam penyajian hasil analisis karena penelitian ini bersifat deskriptif. Maksudnya pendeskripsian dari dari gejala atau keadaan yang terjadi pada objek data penelitian. Interferensi diungkapkan secara apa adanya berdasarkan pada data, sehingga hasil perian ini benar-benar merupakan suatu fenomena bahasa yang sesungguhnya. Data yang sudah dianalisis kemudian diberi penjelasan dibawahnya mengenai jenis interferensi, analisis dan sumber data.

\section{Jenis-Jenis Interferensi Gramatikal Bahasa Indonesia dalam Mahārah Kalām Santriwati KMI Pondok Modern Ar-Risalah Program Internasional}

Dalam penelitian ini, penulis menemukan data-data interferensi gramatikal Bahasa Indonesia dalam mahārah kalām dengan penutur asli bahasa Indonesia yaitu para santriwati Pondok Ar-Risalah. Di bawah ini penulis memaparkan lebih lanjut jenisjenis interferensi dalam mahārah kalām santriwati Pondok Ar Risālah beserta faktor penyebabnya.

\section{Interferensi Morfologis dalam Mahārah Kalām}

Interferensi morfologi terjadi apabila dalam pembentukan katanya suatu bahasa menyerap afiks-afiks bahasa lain. Penyimpangan struktur itu terjadi kontak bahasa 
antara bahasa yang sedang diucapkan (bahasa Indonesia) dengan bahasa lain yang juga dikuasainya (bahasa Arab) (Sudaryanto, 1993: 123). Berikut ini penulis memaparkan analisis dari data interferensi yang ditemukan.

\section{Kesalahan Pembentukan Kata}

- Kesalahan Pembentukan Fi'il menjadi Mașdar

Contoh : kata ذهاب /żihāb/ pada kalimat ذهاب إلى القاعة, merupakan kata berbentuk mașdar yang seharusnya berbentuk fi'il.

- Kesalahan Pembentukan Mașdar menjadi Fi'il

Contoh : kata قرب /qaruba/ pada kalimat قرية قرب المعهد, merupakan kata berbentuk fi'il yang seharusnya berbentuk mașdar

- Kesalahan Pembentukan Fi'il menjadi Ism Fä'il

Contoh : kata مُستَافر /musāfir/ pada kalimat إلي أين مسافر؟, merupakan kata berbentuk ism fä'il yang seharusnya berbentuk fi'il

- Kesalahan Pembentukan Fi'il Nahī

Contoh : pembentukan fi'il nahī pada kalimat لاتكلمت كنلك؟ / lā takalamti/ tidak menggunakan bentuk fi'il amr tetapi fi'il māḍī. Agar bentuk kalimat negasi itu menjadi benar, maka fi'il māộ̀-nya harus diganti menjadi fi'il amr dan memasukkan harf [ ت ] لاتتكلمي /lā tatakallamī/.

\section{Pemajemukan}

Contoh : kata سأهتف مع أمى أبى أمى أبى /ummì abī/ pada kalimat, mengalami pemajemukan seperti dalam bahasa Indonesia, yang dalam bahasa Arab kata tersebut biasa diucapkan dengan /wālidayyā/.

\section{Reduplikasi}

Contoh : kata جميلة جميلة /jamīlah jamīlah/ pada kalimat الإنسان جميلة جميلة jambi, menggunakan reduplikasi yang jika dilihat dari bentuknya kata ini mengalami kerancuan ungkapan, karena bahasa Arab tidak mengenal kata ulang seperti kata tersebut.

Dari data-data di atas, dapat ditarik sebuah kesimpulan tentang adanya pembentukan kata-kata mengandung struktur yang tidak dikenal dalam bahasa Arab. Para santriwati mencoba menggunakan sistem morfologi bahasa Arab yang disesuaikan dengan sistem morfologi bahasa Indonesia. Adanya pencampuran sistem morfologi bahasa Indonesia dengan sistem morfologi bahasa Arab tersebut membuktikan adanya 
peristiwa interferensi gramatikal yang dilakukan oleh para santriwati Pondok Modern Ar-Risalah.

\section{Interferensi Sintaksis dalam Mahārah Kalām}

Interferensi sintaksis terjadi apabila struktur bahasa lain (bahasa daerah, bahasa asing, dan bahasa gaul) digunakan dalam pembentukan kalimat bahasa yang digunakan. Penyerapan unsur kalimatnya dapat berupa kata, frase, dan klausa (Sudaryanto, 1993: 123). Data yang penulis temukan untuk interferensi sintaksis ini banyak sekali, dan dalam analisisnya penulis memberikan beberapa contoh yang sekiranya dapat mewakili bentuk-bentuk interferensi sintaksis para santriwati Pondok Ar-Risalah. Berikut ini penulis memaparkan analisis dari data interferensi yang ditemukan.

\section{Penghilangan Unsur Kalimat}

- Penghilangan Subyek

Contoh : خلاص لماب؟/khalaș lammāa/ mengalami penghilangan Subyek, yang seharusnya diberi subjek agar kalimat tersebut menjadi kalimat tanya yang sempurna dan sesuai dengan kaidah BAS yaitu هل قد إنتهيت؟ / /

- Penghilangan Predikat

Contoh : kalimat أنا الفطور/ana al futūr mengalami penghilangan predikat, Dalam bahasa Indonesia ungkapan ini banyak dipakai dalam ragam bahasa lisan. Namun, dalam bahasa Arab, ungkapan tersebut akan menimbulkan kebingungan.

- Penghilangan Obyek

Contoh : kalimat أنا أدعو قردا/ana ad'u qirdan/, mengalami penghilangan objek, yang seharusnya أدعوك قردا / ad'uki qirdan/

- Penghilangan Kata Tanya

Contoh: kalimat أنت حارسة, نعم؟ /anti harisah, na'am?/, adalah kalimat tanya, tetapi tidak diawali dengan adawat istifham. Untuk itu, kalimat tersebut dapat diperbaiki dengan menambahkan adawat istifham sehingga menjadi هل كنت حارسة ؟ هal kunti harisah?/

- Penghilangan Harf 'Ataf

Contoh : kalimat كنت حرسة القاعة حرسة الحجرة/kuntu harisata al-qā'ah harisata alḥujrah/ mengalami penghilangan Harf 'ațaf. Di antara ḥarf 'ațaf yang sesuai adalah كنت حرسة القاعة و الحجرة و و و و

- Penghilangan Ya'Mutakallim Fi'il Amr 
Contoh : إسأل إلى أختىsinta /isal ilā ukhtī/, kalimat tersebut kurang sempurna karena menghilangkan $y a^{\prime}$ mutakallim . Untuk itu, kalimat tersebut perlu diberi tambahan ya' mutakallim sehingga menjadi إسألى /isalī/

- Penghilangan HarfJar

Contoh : انا أذهب الحمام /ana ażhabu al-ḥamām/ , jika dilihat dari maknanya, kalimat tersebut terasa ada yang janggal yaitu hilangnya huruf yang fungsinya untuk memperjelas kemana si pembicara akan pergi.. Untuk itu, kalimat tersebut dapat diperbaiki dengan menambahkan harf jer yang sesuai dengan kalimat tersebut. Di antara harf jer yang sesuai adalah harf jer إلى /ilä/ yang artinya "ke" sehingga kalimat tersebut menjadi انا أذهب إلى الحمام/ana ażhabu ilā al-ḥamām/.

- Penghilangan Damīr muttașil Ism

Contoh : أنا أستطيع أن أعرف صاحبتى مع الأخلاق الكريمة /ma'a akhlāqi al-karīmah, kalimat tersebut kurang sempurna karena hilang ḍmīr muttașil untuk ism-nya yaitu kata /ma'a akhlāqi al-karīmah/. Untuk itu, kalimat tersebut perlu diberi tambahan ḍamir muttașil yang sesuai dengan ism-nya sehingga menjadi بأخلاقها الكريمة /bi akhlaqihā al-karīmah/.

\section{Penambahan Unsur Kalimat}

- Penambahan HarfJer

Contoh : kalimat من يعرف لمعنى من كلمة القائد /lima'nā min kalimat.../, Penambahan harf jer pada kalimat tanya tersebut kurang tepat, karena dari segi bentuk dan maknanya dalam kalimat, kalimat tersebut sudah dapat dipahami dengan baik. Sehingga, harf jer لمعنى من كلمة /lima'nā min kalimat.../ dapat dihilangkan sehingga menjadi /ma'na/.

- Penambahan Harf 'Ațaf

Contoh : kalimat نتعلم فى الفصل منذ الساعة السابعة وحتى الساعة الواحدة /munżu...wa hatta, Dalam kalimat tersebut harf 'ațf [g] kurang tepat penggunaannya. Karena dalam kalimat tersebut sudah terdapat harf jer منذ/munżu/dan حتى / حنىatta/yang secara fungsi dalam kalimat lebih sesuai untuk menjelaskan maksud pembicaraan. Oleh karena itu penambahan harf 'ațaf tersebut tidak diperlukan.

- Penambahan harfnașab

Contoh : لكى لطلب العلم /likaī lițalabi al-'ilmi/, Dalam kalimat tersebut terdapat ḥarf yang masuk pada fi'il yaitu lam kaī [كى] yang artinya supaya. Dalam konteks pembicaraan pada kalimat tersebut penggunaan lam kaī [كى] kurang tepat baik secara makna maupun dalam bentuk kalimat, karena sudah terdapat harf lain yaitu 
yang artinya "untuk". Pengunaan harf ini lebih sesuai untuk konteks pembicaraan. Sehingga harf lam kaī [كى tersebut sebaiknya dihilangkan dalam kalimat di atas.

\section{Kesalahan Pembentukan Frasa}

- Kesalahan Pembentukan Na'at Man'ūt

Contoh : صف الر ابع /șffu ar-rābi'u/, frasa ini tidak sesuai antara kata pertama yang disebut man'ūt, dan kata kedua yang disebut na'at. Man'ūt dalam frasa tersebut berbentuk nakirah, sementara na'atnya berbentuk ma'rifah. Seharusnya frasa tersebut dibentuk menjadi الصف الر ابع /aṣ-ṣaffi ar-rābi'/.

- Kesalahan Pembentukan Idafah

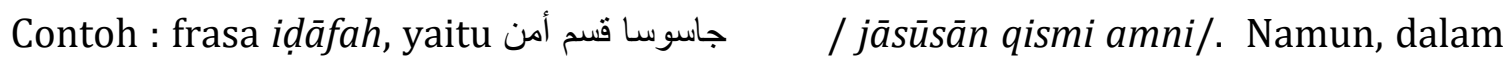
frase di atas, untuk kata ketiga yang berfungsi sebagai muḍāf ilaih, berupa kata yang tak tertentu (nakirah), yaitu tidak ditandai dengan lām ta'rīf. Seharusnya frasa tersebut dapat diperbaiki dengan menambahkan lām ta'rīf pada kata yang berposisi sebagai muḍāf ilaih sehingga menjadi جاسوسا قسم الأمن / jāsūsān qismi alamni/.

- Kesalahan Pembentukan Numeral Contoh : جاسوسة واحدا /jāsūsầ wāhạidān/ Dalam kalimat جاسوسة واحدا / wāḥidān/, frasa ini diungkapkan dengan tidak cermat, karena tidak sesuai antara kata pertama yang disebut $m a^{\prime} d \bar{u} d$, dan kata kedua yang disebut adad. $M a^{\prime} d \bar{d} d$ dalam frasa tersebut berjenis muannaś, sementara adadnya berjenis mudakkar. Dengan demikian terjadi kesalahan. Seharusnya frasa tersebut dibentuk menjadi جاسوسة واحدة /jāsūsah wāḥidāh/.

\section{Kesalahan Letak Kalimat}

- Perubahan Interogativa di Akhir Kalimat Contoh: هيّا ! تشتري ماذا ؟ /hayya tasytarī māżā?/ kata tanya ini seharusnya diletakkan di awal kalimat, tetapi pada kalimat tersebut kata tanya diletakkan di akhir kalimat, yaitu pada posisi setelah subjek. Oleh sebab itu, struktur kalimat itu perlu di ubah menjadi هيّا ماذا ستشترين /māżā satasytarīn / .

- Perubahan Hāl di Awal Kalimat

Contoh : نصلى جماعة العصر /nuṣallī jamā'ata al-așri/ , kalimat ini hāal-nya terletak setelah fi'il, sedangkan hāal dalam aturannya terletak setelah maf'ul bih. Seharusnya kalimat tersebut letaknya menjadi نصلى صلاة العصر جماعة /nuṣallī șalātal al-aṣri jamāatan/. 


\section{Kesalahan Struktur Kalimat}

- Kesalahan I'rab

Contoh: Dalam kalimat نظرت أمُّه /nazartu ummuhu/,kalimat ini tidak sesuai antara i'rab-nya, yaitu maf'ul atau obyeknya ber-harakat dammah [̊]. Seharusnya kalimat tersebut i'rab-nya menjadi نظرت أمَّه /nazartu ummahu/.

- Kesalahan HarfJer Contoh : الصلاة والسلام إلى حبيينا /ilā habībināan, penggunaan huruf / إلى, untuk menyatakan "kepada (orang)" kurang tepat. Seharusnya kalimat tersebut harf jernya menjadi علي حبيين /'alā ḥabībinā/.

- Kesalahan Domir Fi'il

Contoh : أين ذهبثُ عند يوم العطلة؟ /aina żahabtu/, kalimat ini domīr mustatir pada fi'il-

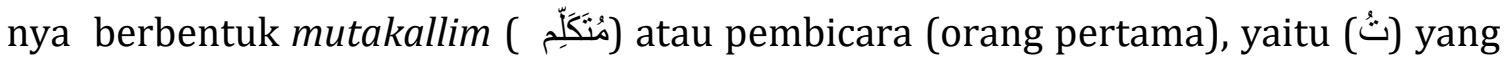
menyimpan makna "saya". Seharusnya kalimat tersebut domīr mustatir-nya ditujukan domīr mukhāțab ( مُخَاطَب atau lawan bicara (orang kedua) sehingga menjadi أين ذهبب /żahabti/.

- Ketidaksesuaian Subyek Predikat

Contoh : بدأت الدرس/badaat ad darsa/, Kalimat tersebut mempunyai subyek kata الدرس /ad darsa / yang berarti “pelajaran”. Kata ini berbentuk mużakar atau berjenis kelamin laki-laki. Untuk itu, predikat dari subyek tersebut juga harus berjenis kelamin mużakar atau berjenis kelamin laki-laki.. Untuk itu, kalimat di atas akan sesuai dengan tata BAS jika predikatnya diganti dengan بدأ /badaa/.

- Ketidaksesuaian Ism Domīr Contoh : والإمامة لصلاة الحاجة وهو من مدبرة /wal imāmatu liṣalāti al hājati wa huwa min mudabbirah/, Dalam kalimat tersebut terdapat ḍamir atau pronomina ه /huwa/, yaitu pronomina yang berarti dia (laki-laki). Padahal pronominal tersebut merujuk ism atau benda muannaś, yaitu kata الإمامة /al imāmatu/. Dari sini seharusnya kata tersebut diganti dengan pronomina هی /hiya/.

- Ketidaksesuaian Ism Mauṣūl

Contoh : رئيسة الجلسة الذى قد أعطاتنى فرصة غالية /raīsatul jalsati al-lażī../, Dalam kalimat tersebut didapati kata sambung الذى yang berbentuk mużakkar tunggal. Akan tetapi, مata sambung tersebut digunakan untuk menerangkan kata مقيمة رائيسة الجلسة /raīsatul jalsati/ yang berjenis muannaś. Dengan demikian penggunaan kata sambung ini tidak tepat. Sebagai gantinya, seharusnya digunakan kata التى /al- latī/.

- Ketidaksesuaian Ism Isyārah 
Contoh : ذلك أستاذه /żalika ustāżah/ kata tunjuk untuk ism mużakkar atau laki-laki yang digunakan untuk menunjuk kepada ism muannas. Seharusnya kalimat tersebut dapat diperbaiki dengan kata tunjuk pada kalimat ذلك أستاذه /żalika ustāżah/ menjadi ت تلك أستاذه /tilka ustāżah/.

- Ketidaksesuaian Mubtada' khobar Contoh : أكثر من الناس يفكر أنه أمة رسول الله صلى الله عليه و السلام /akśaru min an nāsi yufkiru.../ Dalam kalimat di atas mubtada'nya berbentuk jama', maka khabar pun harus berbentuk jama'. Hal demikian tidak terjadi pada kalimat أكثر من الناس يفكر /aksiaru min an nāsi yufkiru/di atas. Kalimat ini memiliki khabar yang berbentuk mufrad, أكثر من الناس يفكرون /akśaru min an nāsi yufkirūn/.

- Ketidaksesuaian Atf Ma'țūf

Contoh : أقراء القرأن وتعلم فى القعاعة /ta'allamu/ katam/ terjadi ketidakselarasan bentuk kata dengan kata sebelumnya. kata ini berbentuk mașdar sedangkan kata sebelumnya berbentuk fi'il. Maka kalimat di atas mengalami أتعلم kesalahan bentuk kata, yang seharusnya berbentuk fi'il, sehingga menjadi /ata'allamu/

- Nakirah Ma'rifat

Contoh : ذهبت إلى مدرسة ثانوية / ilāa madrasatin sāannawiyatin/ pada kata إلى مدرسة ثانوية madrasatin ṡānawiyatin/ berbentuk nakirah. Ism pada kalimat tersebut memiliki kategori yang sulit ditentukan. Kepekaan rasa bahasa dan kecermatan menjadi modal utama untuk mengetahui ism-ism mana yang harus ditulis dalam bentuk ma'rifah karena maksud atau objeknya sudah mafhūm dalam konteks pembicaraan. Jadi kalimat tersebut seharusnya diucapkan dalam bentuk ma'rifat sehingga menjadi madrasati śānawiyati/ karena makna ini sudah dipahami sasaran maksudnya oleh pembicara.

- Aspektualitas

Contoh : أقر اء الكتب و قرأت القرأن /aqrau al kutub wa qara'tu al qurana Kalimat tersebut mengandung dua verba, yaitu أقراء /aqrau/dan أقراء qara'tu/. Verba / أتر / أت / adalah verba muḍari', yaitu verba yang digunakan untuk perbuatan yang sedang atau akan dilakukan. Sementara verba kedua, قرأت / qara'tu/, berbentuk māḍi, atau bentuk lampau. Dengan demikian, kalimat tersebut menggunakan dua verba yang secara aspek tidak sesuai. Kalimat ini, secara aspek mengalami kerancuan makna. 
Hal ini terlihat jelas ketika diterjemahkan ke dalam bahasa Indonesia, sebagai berikut; saya (sekarang) membaca buku dan saya (dulu/telah) membaca al-quran. Dengan kesalahan yang ada pada kalimat penggunaan verba, maka makna kalimat di atas menjadi rancu.

Dari data-data di atas, dapat di tarik kesimpulan, bahwa kalimat-kalimat di atas merupakan contoh bahasa keseharian para santriwati Pondok Ar-Risalah dalam berbicara bahasa Arab. Ungkapan-ungkapan yang digunakan dalam bahasa keseharian santriwati di atas mengalami kesalahan, karena adanya perbedaan sistem bahasa Indonesia dan bahasa Arab. Jika dilihat lagi, ungkapan-ungkapan yang digunakan oleh para santriwati di atas, adalah ungkapan bahasa Indonesia yang di Arabkan. Dengan kata lain, ungkapan-ungkapan tersebut di atas adalah percampuran antara dua bahasa, bahasa Arab dan bahasa Indonesia. Bahasa Arab digunakan dalam aspek kosakatanya, sedangkan sistemnya menggunakan kaidah dalam bahasa Indonesia.

\section{Faktor-Faktor Yang Melatarbelakangi Interferensi Gramatikal Bahasa Indonesia Dalam Mahārah Kalām Santriwati KMI Pondok Modern Ar-Risalah Program Internasional}

Interferensi Gramatikal Bahasa Indonesia dalam Mahārah Kalām yang terjadi pada Santriwati KMI Pondok Modern Ar-Risalah Program Internasional Ponorogo dilatarbelakangi oleh beberapa fakror berikut:

\section{Perbedaan Sistem Bahasa Pertama Atau Bahasa Kedua (Interlingual Transfer)}

Dalam data yang penulis temukan, faktor interlingual transfer para santriwati ini mencakup morfologi, dan sintaksis. Hal ini terjadi adanya kontak antara bahasa Arab dan bahasa Indonesia, yang jika dilihat dari sistemnya kedua bahasa ini memiliki perbedaan. Sebagai contohnya, Penghilangan Subyek, Aspektualitas dan lain sebagainya. Adanya sistem antara bahasa Arab dan bahasa Indonesia sering memunculkan kesulitan-kesulitn dalam berbahasa, khususnya bagi pemula yang baru belajar bahasa Arab. Dari contoh tersebut dapat disimpulkan bahwa faktor perbedaan sistem bahasa pertama atau bahasa kedua (interlingual transfer) menyebabkan peristiwa interferensi dalam mahārah kalām santriwati Pondok Ar-Risālah.

\section{Analogi (persamaan yang berlebihan)}

Para Santriwati mengalami kesalahan dalam menggunakan kosakata yang disebabkan oleh kesamaan unsur antara bahasa pertama dan bahasa kedua, misalnya 
penggunaan kata-kata serumpun (Bentuk yang sama dari kata dalam dua bahasa dengan fungsi atau makna yang berbeda). Data yang penulis temukan, ada beberapa kaidah bahasa Indonesia yang digunakan oleh para santriwati yang memiliki kesamaan unsur dengan bahasa Arab, seperti dalam kesalahan pembentukan frasa. Dari contoh tersebut dapat disimpulkan bahwa adanya analogi yang berlebihan dalam menggunakan kaidah yang antara bahasa Indonesia dan bahasa Arab menyebabkan peristiwa interferensi dalam mahārah kalām santriwati Pondok Ar-Risālah.

\section{Rendahnya Kesetiaan Pemakai Bahasa Penerima}

Tipisnya kesetiaan dwibahasawan terhadap bahasa penerima cenderung akan menimbulkan sikap kurang positif. Hal itu menyebabkan pengabaian kaidah bahasa penerima yang digunakan dan pengambilan unsur-unsur bahasa sumber yang dikuasai penutur secara tidak terkontrol. Data yang penulis temukan, banyak kaidah atau struktur bahasa Indonesia yang masih digunakan oleh para santriwati ketika berbicara bahasa Arab. Contohnya adalah seperti kaidah i'rab dan kesesuaian aspektualitas fi'il.

\section{Kebutuhan Akan Sinonim}

Karena adanya sinonim ini cukup penting, pemakai bahasa sering melakukan interferensi dalam bentuk penyerapan atau peminjaman struktur baru dari bahasa sumber untuk memberikan sinonim pada bahasa penerima. Dengan demikian, kebutuhan struktur gramatikal yang bersinonim dapat mendorong timbulnya interferensi.

\section{Transfer Struktur Bahasa karena Terbawanya Kebiasaan Dalam Bahasa Ibu}

Ditemukan bahwa para santriwati menggunakan kebiasaan berbahasa dalam bahasa Indonesia. Sebagai contohnya para santriwati sering mengucapkan kata dengan kaidah gramatika bahasa Indonesia, seperti, ketika dalam penggunaan interogatove di akhir kalimat.

\section{Kesimpulan}

Berdasarkan keseluruhan uraian dan analisis tentang "Interferensi gramatikal bahasa Indonesia dalam mahārah kalām Santriwati Kulliyatul Mu'allimat Al-Islamiyah Pondok Modern Ar-Risalah Program Internasional Ponorogo, penulis dapat mengambil kesimpulan sebagai berikut: 1) Interferensi yang terjadi pada para santriwati Pondok Ar-Risalah terkait pada aspek morfologi : Kesalahan Pembentukan Kata, Reduplikasi dan Pemajemukan, sedangkan Sintaksis : Penghilangan Unsur Kalimat, Penambahan 
Unsur Kalimat, Kesalahan Pembentukan Frasa, Kesalahan Letak Kalimat dan Kesalahan Struktur Kalimat. 2) Faktor-faktor yang melatarbelakangi terjadinya interferensi gramatikal bahasa Indonesia dalam mahārah kalām Santriwati KMI Pondok Modern Ar-Risalah adalah perbedaan sistem bahasa pertama atau bahasa kedua (interlingual transfer), analogi (persamaan yang berlebihan), tipisnya kesetiaan pemakai bahasa penerima, kebutuhan akan sinonim dan transfer struktur bahasa karena terbawanya kebiasaan dalam bahasa ibu. Berdasarkan data interferensi yang di dapat oleh penulis, ditemukan bahwa semua faktor tersebut sangat berperan dalam peristiwa interferensi gramatikal bahasa Indonesia mahārah kalām Santriwati KMI Pondok Modern ArRisalah.

\section{Daftar Rujukan}

Abdulhayi dkk. Interferensi Gramatikal Bahasa Indonesia dalam BahasaJawa. Jakarta: Pusat Pembinaan dan Pengembangan Bahasa Departemen Pendidikan dan Kebudayaan, 1985.

Al Ghalayayni, Syaikh Mustafa. Jami'ud Durus al-'arabiyyah. Beirut: Daarul Bayan, 2008.

Alkaf, Idrus H. Cara Cepat dan Mudah Belajar Sendiri Bahasa Arab. Bandung: Hasyimi, 2001.

Alwasilah, A Chaedar. Sosiologi Bahasa. Bandung: Angkasa, 1990.

Alwi. Hasan. Tata Bahasa Baku Bahasa Indonesia. Jakarta: Balai Pustaka, 2003.

Budiarty, Any. "Interferensi Bahasa Indonesia ke Dalam Bahasa Inggris pada Abstrak Jurnal Ilmiah”. Jurnal: Bahasa dan Seni, Vol. 41, No. 1, Februari 2013.

Chaer, Abdul \& Leonie Agustina. Sosiolinguistik Perkenalan Awal. Jakarta: Rineka Cipta, 2004.

Denes,I Made. dkk. Interferensi Bahasa Indonesia Dalam Pemakaian Bahasa Bali di Media Massa. Jakarta: Pusat Pembinaan dan Pengembangan Bahasa Departemen Pendidikan dan Kebudayaan, 1994.

Effendi, Ahmad Fuad. Metodologi Pengajaran Bahasa Arab. Malang: Misykat: 2009.

Fakhrurrozi, Aziz \& Erta Mahyudin. Pembelajaran Bahasa Arab. Jakarta: Direktorat Jenderal Pendidikan Islam Kementerian Agama, 2012.

Hermawan, Acep. Metodologi Pembelajaran Bahasa Arab. Bandung: Remaja Rosdakarya, 2011.

Husein, Hasan. Maharatu At-Tadris Ru'yatu Fi Tanfidzi At Tadris (Cet.3). Kairo: 'Alimu Al Kutub, 2006. 
Kussemiarti, Agnes Emmie. Interferensi Fonologis Bahasa Indonesia dalam pelafalan bunyi Ucapan Bahasa Inggris (Studi Kasus Mahasiswa PTS di Kotamadya Yogyakarta). Yogyakarta: Tesis pada PPS. UGM, 2003.

Ma'luf, Louis. Al-Munjid Fi al- Lughah Wa al-A'lam. Beirut: Dar al-Masyriq, 1973.

Mahsun. Metode Penelitian Bahasa: Tahapan Strategi, Metode, dan Tekniknya,Ed. Revisi. Jakarta: Rajawali Pers, 2012.

Moleong, Lexy J. Metodologi Penelitian Kualitatif. (cet. ke-30). Bandung: Remaja Rosdakarya, 2012.

Muin, Abdul. Analisis Kontrastif Bahasa Arab dan Bahasa Indonesia. Jakarta: PT. Pustaka Al-Husna Baru, 2004.

Munawir, Ahmad Warson. Kamus Al Munawir Arab Indonesia Terlengkap. Surabaya: Pustaka Progessif, 2000.

Munawari, Akhmad. Belajar Cepat Tata Bahasa Arab Program 30 Jam (Nahwu Sharaf Sistematis). cet. 10. Yogyakarta: Nurma Media Idea, 2006.

Mustofa, Syaiful. Strategi Pembelajaran Bahasa Arab Inovatif. Malang: UIN Maliki Press, 2011.

Ngatipan. Interferensi dalam Kemahiran Kalam dan Qira'ah Siswa MTs Negeri Rongkop Gunungkidul. Yogyakarta: Tesis pada PPS. UIN Sunan Kalijaga, 2014.

Nuha, Ulin. Metodologi Super Efektif Pembelajaran Bahasa Arab. Yogyakarta: Diva Press, 2012.

Rindjin, Ketut. Dkk. Interferensi Gramatikal Bahasa Bali Dalam Pemakaian Bahasa Indonesia Murid Sekolah Dasar di Bali. Jakarta: Pusat Pembinaan dan Pengembangan Bahasa Departemen Pendidikan dan Kebudayaan, 1981.

Rosyidi, Abd Wahab dan Mamlu'atul Ni'mah. Memahami Konsep Dasar Pembelajaran Bahasa Arab. Malang: UIN Malang Press, 2011.

Sa'diyah, Za'imatus. Interferensi Gramatikal Bahasa Indonesia ke dalam Bahasa Arab Tulis Mahasiswa Tingkat IV Ma'had Ali Bin Abi Thalib UMY. Yogyakarta: Tesis pada PPS. UGM, 2009.

Schulz, Eckehard. Bahasa Arab Baku dan Modern. Yogyakarta: LKIS, 2012.

Soeparno. Dasar-dasar Linguistik Umum. Yogyakarta: Tiara Wacana Yogya, 2002.

Sudaryanto, dkk. Metode dan Aneka Teknik Analisis Bahasa: Pengantar Penelitian Wahana Kebudayaan Secara Linguistik. Yogyakarta: Duta Wacana, 1993.

Sugiyono. Memahami Penelitian Kulitatif. Bandung: ALFABETA, 2007. 
Suindratini, Dewa Ayu Nyoman. Dkk. "Interferensi Bahasa Bali Dan Bahasa Asing Dalam Cerita Lisan Bahasa Indonesia Kelas VII Siswa SMP Negeri 10 Denpasar”. E-Journal Program Pascasarjana Universitas Pendidikan Ganesha Program Studi Pendidikan Bahasa Dan Sastra Indonesia, Vol. 2 Tahun 2013.

Suja'i. Inovasi Pembelajaran Bahasa Arab Strategi Dan Metode Pengembanagan Kompetensi (cet. 1). Semaranag: Walisongo Press, 2008.

Tarigan, Henry Guntur. Pengajaran Semantik. Bandung: Angkasa, 2009.

\& Djago Tarigan. Pengajaran Analisis Kesalahan Berbahasa. (edisi revisi). Bandung: Angkasa, 2011.

Yusuf, Suhendra. Teori Terjemah: Pengantar ke Arah Pendekatan Linguistik dan Sosiolinguistik. Bandung: Mandar Maju, 1994.

Zaini, Hisyam. Slang Santri Kulliyatul Muallimin Al-Islamiyyah Pondok Modern Darussalam Gontor Ponorogo, (tidak diterbitkan). Yogyakarta: Disertasi pada PPS. UIN Sunan Kalijaga, 2011. 